\title{
UN ASPECTO DEL CRISTIANISMO EN ITÁLICA Y SU PLASMACIÓN EN EL REGISTRO FUNERARIO: LAS EXCAVACIONES DE 1903
}

\section{A FUNERARY ASPECT OF CHRISTIANISM IN ITÁLICA: THE 1903 EXCAVATIONS}

\author{
por \\ JoSÉ MARÍA GONZÁLEZ PARRILLA
}

a Don Manuel Pellicer Catalán por ofrecernos sus conocimientos sobre Itálica.

RESUMEN Los materiales arqueológicos encontrados en las excavaciones de 1903, suponen un primer impulso en el estudio de la introducción del cristianismo en Itálica.

Con este trabajo se pretende una primera aproximación al estudio de estos materiales atribuidos a la presencia del cristianismo en la Colonia Aelia Augusta Itálica.

\begin{abstract}
The archaeological found materials in the excavations of 1903, suppose a first impulse in the study of the introduction of the christianity in Itálica.

With this work we purport a first approximation to the study of these materials attributed to the presence of the cristianity in Colonia Aelia Augusta Itálica.
\end{abstract}

Palabras claves Inicio del cristianismo. Bética. Itálica. Registro funerario.

Key words First cristianism. Baetica. Italica. Funerary evidence.

\section{INTRODUCCIÓN}

La necrópolis de la Vegueta situada al este de la ciudad de Adriano es la más conocida de Itálica ya que las excavaciones de 1903 pusieron al descubierto un número importante de tumbas. El Profesor M. Pellicer Catalán escribe sobre esta necrópolis: "Es la necrópolis más densa de Itálica y está situada al oriente de Santiponce, en los alrededores del teatro y, más bien, en su parte septentrional, donde deben encontrarse las tumbas más primitivas, quizás de época republicana e inicios del imperio, pero su gran profundidad, a más de tres metros sobre el nivel del suelo incrustadas en la capa freática, dificultan gravemente su excavación. Esta necrópolis bordearía la vía de Itálica a Hispalis y a Emerita Augusta [...]. 
En esta necrópolis, según las tumbas excavadas, en las más superficiales predomina el rito de la inhumación, habiéndose hallado dieciséis sarcófagos de plomo en fosas con paredes de ladrillos, estucadas o revestidas de mármol y cubierta con tégulas, posiblemente a doble vertiente. Seis sarcófagos presentan decoración, fechable a finales del siglo III ó IV d.C. más arcaicos son algunos enterramientos, los menos de incineración en urnas de plomo o de cerámica, fechables en el siglo I y II p.C. [...]" (Pellicer 1999: 184-185).

La introducción del cristianismo en la Península Ibérica está aún a merced de la interpretación y de las hipótesis adoptadas por los distintos autores.

Las dos hipótesis más aceptadas son las siguientes:

La primera de ellas se decanta por la introducción del cristianismo en Hispania desde África. Los autores hablan de varias manifestaciones que relacionan la Península Ibérica con el norte del continente africano. Varios ejemplos como la Carta Sinodial de San Cipriano a las comunidades cristianas de Astorga, León y Mérida, constituyen una premisa válida para esta hipótesis. Estas comunidades acuden a Cartago para dirimir sus contiendas, ello puede deberse a la influencia de estas iglesias en la expansión del cristianismo hispano (Alonso 1978: 41).

La segunda hipótesis habla de una introducción del cristianismo en Hispania a través de las relaciones de las ciudades más importantes con Oriente y a la presencia en ellas de colonias de judíos hacia los que se dirige el primer proselitismo (García Iglesias 1974: 324).

La arqueología evidencia a través de los restos materiales, en este caso los funerarios, cambios en determinados aspectos del mundo socio- cultural romano, manifestados a través de la introducción de esta nueva fe.

Son esenciales estos materiales para construir la historia del cristianismo en Itálica ya que constituyen un apoyo cronológico fundamental para situarlos en la historia de la ciudad.

Muchos son los factores que nos hablan de la existencia de la nueva fe, materiales arqueológicos, estructuras arquitectónicas, que conforman un elenco de posibilidades que van a plasmar una realidad que podemos documentar a partir del siglo IV d.C

Según algunos autores (Alonso1978: 43), este influjo tiene su punto más álgido a partir de la segunda mitad del siglo IV y durante los siglos V y VI d.C, por lo que coincide cronológicamente con la mayoría de los materiales arqueológicos que vamos a describir en este trabajo.

\section{LAS EXCAVACIONES DE 1903}

Las excavaciones que se fueron haciendo en Itálica desde la última década del siglo XIX sacaron a la luz numerosos materiales que aún hoy siguen inéditos. Estos materiales hablan de la importancia de las necrópolis que la ciudad debió tener durante los ocho siglos en que tenemos constancia de su existencia.

En el marco de estos trabajos se sitúan los que se llevaron a cabo durante el verano de 1903. Las obras que se acometieron en la Vegueta de Santiponce para unir Cala con San Juan de Aznalfarache mediante ferrocarril, dejaron a su paso por este pueblo unos restos arqueológicos de los que la Comisión Monumentos de la provincia de Sevilla tuvo noticias. Esta comunicación hizo que su secretario, Manuel Fernández López, se personara en los trabajos para supervisar los materiales arqueológicos que estaban apareciendo y como consecuencia de los cuales tenemos la única monografía que versa sobre el tema funerario en Itálica hasta el momento.

El registro que guarda el Museo Arqueológico Provincial de Sevilla, revela la ingente cantidad de materiales que en él se depositaron y que salieron de estas "excavaciones arqueológicas". 
Posteriormente se han llevado a cabo otros trabajos en esta zona de la Vegueta. Así en 1974 se acometieron unas excavaciones dirigidas por A. M. Canto y de Gregorio que proporcionaron una información muy valiosa. Estos trabajos sacaron a la luz, según escribe su autora, un "barrio tardío" que además proporcionó un muro al que se le adosaba una tumba de inhumación. Según sus conclusiones, este muro podría tratarse el final de la necrópolis por esta zona' '(Canto 1982: 242).

Volviendo a la monografía de M. Fernández López titulada Excavaciones en Itálica (1903), fue publicada en 1904 y simplemente relata como las tumbas fueron apareciendo gracias a la pericia del capataz de la obra y a los trabajos esforzados de los obreros. Dicho capataz llamado José Jiménez Sánchez, vecino de Santiponce es considerado por algunos autores como R. Amador de los Ríos como uno de los mayores destructores del yacimiento del que incluso llega a decir que destrozaba muros para hacer cal (Ríos 1911: 92). Su experiencia se demuestra en otras excavaciones de A. M. Huntington en 1898 en el que aparece entre la relación de obreros que este autor da en su libro inédito La Itálica ${ }^{2}$. Aparece como uno de los vendedores más importante de inscripciones funerarias de las cuales muchas fueron compradas por Doña Regla Majón, Condesa de Lebrija.

Este pequeño perfil nos da una idea de la persona que llevaba las excavaciones, ya que Fernández López solo vigilaba los trabajos y eso se nota perfectamente en su libro. Por su texto es imposible poner en pie la excavación, la explicación es muy sencilla y es que él mismo dice que la experiencia de este hombre era la que dictaba las directrices de los trabajos y esto es alabado por Fernández López: "Al asomar nosotros por la necrópolis disponíase el capataz a practicar nuevos ensayos que ojalá y hubiera hecho, pues de seguro nos da otro alegrón. Se trata, en efecto, de un hombre de habilidad extraordinaria para esta clase de operaciones. En donde los demás nada ven él siempre ve algo; y como empuñe la espiocha y la hunda en tierra difícilmente se irá de vacío" (Fernández López 1904: 57).

Por ello es que la información que podemos extraer de esta monografía es parcial. Varios son los motivos:

1. La situación de las tumbas es referenciada desde dos estructuras que aparecieron en el transcurso de estos trabajos, lo cual es inútil ya que no van acompañadas de un plano general en el que se puedan observar ni las estructuras, ni las tumbas.

2. No ofrece profundidades de las tumbas y la distancia entre ellas es referida de una forma puntual, con lo cual es imposible hacerse una idea global de situación.

Con estos dos motivos es suficiente para hacerse a la idea de como transcurrió la única "excavación en extensión" de una necrópolis en Itálica.

A pesar de ello, y como hemos dicho más arriba, ofreció unos materiales que nos dan la posibilidad de conocer algo de la necrópolis en la que se desarrollaron los trabajos.

Después de observar detenidamente sus palabras, podemos extraer varias conclusiones:

1. Parece que, por la tipología de las tumbas, se trataba de dos planos distintos de tumbas. El primer plano es el en que describe un tipo de tumbas más sencillas y que estaban formadas por simples tégulas a dos aguas con dos verticales que cerraban la cabeza y pie de la tumba, en la cual el cadáver se depositaba directamente sobre el suelo. Estas tumbas han sido constatadas en excavaciones posteriores realizadas por J.M. Luzón Nogué en los años $60^{3}$ y por R. Corzo Sánchez en los años 80 , en el pórtico del teatro.

1. Algunos de los materiales encontrados en esta tumba son tardíos

2. Este dato es recogido en (García Mazas 1962)

3. El informe y las fotografías siguen inéditas. Tenemos que dar las gracias a J.M. Rodríguez Hidalgo por su ayuda para localizarlas. 
2. Un segundo plano pudo dar una tipología de tumbas más elaboradas. Son tumbas de inhumación, al igual que las primeras, en las que aparecen tégulas verticales, la cuales llevan el interior lucido en color crema. Algunas de estas tumbas aparecen cubiertas con losas de mármol o simples tégulas, encima llevan otras tégulas puestas a la capuchina.

Es este tipo de tumbas eran las que contenían los sarcófagos de plomo que han sido atribuidos o asociados a enterramientos correspondientes a cristianos.

Esta atribución al mundo cristiano de las estructuras que aparecieron en esta necrópolis, es ya apuntado por Fernández López que interpreta la aparición de cerámicas y vidrios dándoles un uso propio del mundo cristiano:

"Toda esta vajilla se utilizó en los banquetes que los cristianos celebraban bajo la presencia del cura o del obispo el día de los funerales de sus hermanos difuntos, banquete en el que los comensales deseaban la gloria eterna al que partiera de este mundo y en el que ellos mismo se confortaban, recordando aquel otro que Jesucristo ofrece a los suyos allá en los cielos. [...]

Mucho de estos vasos eran dejados sobre las sepulturas como piadoso recuerdo de los asistentes a la fiesta funeraria" (Fernández 1904: 27).

Estas sepulturas que contenían estos materiales, evidentemente no todas correspondieron a cristianos, entre otras cosas por que en algunas de ellas aparecieron inscripciones funerarias en las que el uso de fórmulas epigráficas como el D.M.S., denota aún su carácter pagano.

\section{MATERIALES ARQUEOLÓGICOS Y ESTRUCTURAS ARQUITECTÓNICAS ATRIBUIDAS AL MUNDO CRISTIANO QUE HAN APARECIDO EN LAS NECRÓPOLIS DE ITÁLICA}

Las excavaciones referidas de 1903 pusieron al descubierto dos grandes estructuras que fueron interpretadas por su autor como una basílica paleocristiana y como una estructura en forma de cruz griega. La primera de ellas es descrita de la siguiente manera: "el recinto limitado por la fábrica de mortero, desescombrado hasta la profundidad de m. 1'20, resultó ser una nave despavimentada, larga y ancha de metros 14'50 y 5'60, orientada de sur a norte, y terminada en ábside semicircular, con puerta arqueada en el fondo y algo a la derecha que daba ingreso a una pequeña cueva subterránea, abierta en el espesor del muro. La nave estaba dividida en tres compartimentos casi iguales por paredes acitaradas [...]. en el tercio superior, a poniente, se advierten vestigios de una puerta grande; y en el inferior, arrimados a la pared de la izquierda, hay dos pequeños cubos de mortero" (Fernández López 1904: 63).

La segunda la describe de la siguiente forma: “... limpiaron dos de los frentes y vióse que se trataba de una hermosísima cruz griega, con brazos de m. 7'80 en total, [...] construida en piedra franca, alta de metros 1'80 y formada por cuatro segmentos de círculos contrapuestos, rematados por elegante imposta de cinco filetes. La cuerda de los arcos es de cuatro metros. A consecuencia de la manera como están colocados los segmentos de círculo los brazos de la cruz van ensanchando hacia los extremos, ensanchamiento disimulado artísticamente con suplementos triangulares de piedra, largos de m. 0'95, acanalados por ambas caras y semejando remates lanceolados del mejor gusto. Por último, sobre el centro o macizo de la cruz hay una especie de plinto rectangular, hecho de sillaretes y con metros 1' 80 de largo por 0' 20 de altura" (Fernández López 1904: 23).

Del resto de materiales arqueológicos, llama la atención los sarcófagos de plomo, tanto por la cantidad de los aparecen como por su decoración. Estos sarcófagos aparecen en gran parte de la bibliografía italicense como salidos de las distintas excavaciones. Algunos de los que vamos a describir en este trabajo ya fueron publicados por C. Sainz de Arizmendi (1907) o por A. García y Bellido (1960). 
Un claro ejemplo de esto que decimos son los sarcófagos que aparecieron en las excavaciones de 1903. La mayoría de ellos se conservan en el Museo Arqueológico de Sevilla y son de gran utilidad ya que conocemos el contexto arqueológico en el que aparecieron, lo que nos puede ayudar a conocer su cronología.

Vamos a realizar un somero repaso por los que relata Fernández López incluyendo el contexto arqueológico en el que aparecieron.

1. "En un espacio rectangular, limitado por cuatro muretes de ladrillo romano con m. 0'40 m de altura, estaba prisionado un ataúd o caja sepulcral de plomo, orientada de este a oeste y depositada directamente sobre la tierra. [...]

La caja sepulcral lisa y sin adornos, con m. 1'94 de largo, 0'47 y 0'35 de ancho y alto por la cabecera y 0'33 y 0'30 por los pies". Su referencia de deposito es la 3153 .

2. "Construcción rectangular, larga de m. 2'20 y de 1'30 y 0'85 para el ancho y la altura, [...] en el centro de la construcción apareció una especie de canal de m. 0' 15 de anchura, con las paredes y cubiertas formada por dos hiladas de ladrillos romanos, todo afirmado con buenísima mezcla.[...] Por debajo de los ladrillos, cerrando la fosa, había tres grandes losas cuadradas [...], fuertemente afirmadas y con tres a modo de fajas en la cara superior, compuesta cada una de cuatro canalillos incisos y paralelos. [...]. La losa correspondiente a la cabecera tenía grabados el crisma constantiniano, la letra alfa y cuatro hoyitos dispuestos en forma de ele mayúscula que bien puede representar un ancla: situada a los pies, una palma y otro signo parecido a la letra omega.[...].

Quitadas las losas, apareció un ataúd o caja sepulcral de plomo, larga de m. de 1'89 y 0'50 y 0'35 para el ancho de cabecera y pies. La tapa lucia en el centro y al largo de la cara superior una faja ornamental figurando hojas lanceoladas partiendo de tallos centrales y ramitos de cinco vástagos en los espacios inferiores. La misma composición repítese en las fajas transversales que la cortan y la recorren los bordes doblados". Su referencia de depósito es la 3156.

3. "Cuatro muretes de ladrillos, con m. 0'35 de altura, cerrados por tres losas de barro ferruginoso, completamente reblandecidas por la humedad, con una palma grabada en la del centro.[...]

Levantado que fueron los pedazos, se encontró un ataúd de plomo, largo de m. 1'24, colocado directamente sobre el suelo y adornado los bordes doblados de la tapa con un tallado serpenteante alternando con grupos de hojas". Su referencia de depósito es la 3158.

4. "'macizo rectangular con $\mathrm{m}$. 2'50 de largo por 0'80 de ancho y 0'70 de altura, hecho de grandes ladrillos romanos. Quitadas la hiladas superiores, aparecieron las tres losas de costumbre, con sus fajas ornamentales diagonales y transversa pero sin crisma ni letras griegas: únicamente la del centro tenía unos hoyitos dispuestos en forma de ele mayúscula. [...].

Los muretes, a pesar de la buenísima mezcla empleada en su fabricación, estaban desnivelados en el sentido de la longitud, deformando la tapa del ataúd de plomo que aprisionaban. Éste, liso y sin adornos, medía de largo $m$. 1'95, de alto y ancho por la cabecera m 0'35 y 0'50, y por los pies m. 0'27 y 0'37'. Referencia de depósito 3207.

5. “... Sepultura con luz interior de metros 1'05 y 0'35 para el largo y ancho, formada por muretes altos de m. 0'36, bien enlucidos por dentro y cubiertos con tres hiladas de ladrillos, sobre puestas a dos losas del barro ferruginoso tantas veces mencionado, sin marca alguna especial.

Retirados ladrillos y losas, apareció un ataúd de plomo en buen estado de conservación, largo de m. $0 ' 90$ y con faja central en la tapa recorriendola de cabeza a pies, cortada por la otras tres, adornadas éstas y aquellas con tallos serpenteantes alternando con hojas. El mismo motivo repítese en la faja de los bordes doblados". Referencia de depósito 3160. 
6. "Monumento de ladrillos con un ataúd de plomo, liso y sin adornos".

7. "Fábrica de ladrillos y de m. 2'52, 0'91 y 0'98 para el largo, ancho y altura exteriores. Alojaba en su interior un ataúd de plomo, largo de m $1^{\prime} 78$ y 0'55 y 0'36 para el alto de cabecera y pies, con faja central a todo el largo de la tapa, cortada por tres transversales, éstas y aquellas llenas de hojas cuadrifolias en relieve. El mismo motivo repítese en la faja de los bordes". Referencia de depósito 3210.

8. "Entre ellos descubrimos una orientada de norte a sur, con muretes de m. 0'35 de altura, perfectamente labrados y enlucidos, cubierta con tejas horizontalmente colocadas y con un ataúd de plomo, largo m. 1'14 y 0'33 y 0'23 para el ancho de cabecera y pies. Este lleva en la tapa dos fajas que se cruzan en tres puntos, consistiendo los adornos en una cinta ondulante que describe ángulos redondeados y contrapuestos, ocupados por discos o botones". Referencia de depósito 3212.

9. "Levantadas las losas de la sepultura dejada pendiente la tarde anterior y deshechos los muretes, sacamos un ataúd de plomo en estado de conservación tal que parecía acabado de salir de las manos del artífice. Mide de largo m 1'78 y 0'54 y 0'36 para el ancho de cabecera y pies. Lleva en la tapa dos fajas que se cruzan en tres puntos, recorridas en toda su extensión por dos cintas que se desarrollan en espiral simulando eses conchiformes y pequeño fleco formado de prismas hendidos. Igual adorno se repite en los bordes doblados de la tapa.

10. "Sepultura también de muretes de ladrillo, cubierta con tejas colocadas en sentido horizontal y con ataúd o caja sepulcral de plomo, muy picado el fondo y sin adornos, y larga de m. 1'80 y 0'47 y 0'37 para el ancho de cabecera y pies". Referencia de depósito 3209.

11 y 12. "Se trataba, pues, de dos sepulturas orientadas de este a oeste y en tan inmediato contacto que pudieran tomarse por una sola de no tener las dos sus muretes propios.

Desescombradas que fueron en la medida necesaria, levantamos las losas, dos de las cuales, una para cada sepultura, llevan la cruz conmissa o en tau, [...]

El primer ataúd extraído mide de largo m. 2 y 0'52 y 0'36 para el ancho de la cabecera y pies. Recorre a tapa en toda su longitud una faja central cuyos adornos consisten en discos o botones, lazos colgantes y hojas en combinación con el mejor efecto. La misma faja con iguales motivos repítese en los bordes doblados de la tapa. Los vanos resultantes entre éstos y la faja central ocúpanlos emperlados que dibujan en sus cruzamientos espacios romboidales. El segundo ataúd liso y sin adornos, presenta alguna que otra picadura de poca importancia. Mide de largo m. 1'89 y 0'56 y 0'43 para el ancho de cabecera y pies". Referencia de depósito 3213 y 3214.

13. "Quitado el fondo, aparecieron tres tejas romanas colocadas en sentido transversal, cogidas las juntas con buena mezcla; después, dos hiladas de ladrillos puestas al largo o cabecera a pies, asentadas sobre gruesa torta de arena y cal y con canal intermedio para salida de aguas; luego otras tres tejas; y por último, un ataúd de plomo dentro de la correspondiente sepultura, [...].

El ataúd o caja sepulcral mide de largo m. 1'70, de alto m. 0'35, de ancho m. 0'55 y 0'40. La tapa, con los bordes doblados lisos, lleva en la cabecera y pies dos anchas fajas que se cruzan en aspa y otra igual, central, que une los cruces. Los adornos consisten en discos o botones de distintos tamaños, olivas, lazos y hojas lanzeoladas en combinación caprichosa y de buen gusto". Referencia de depósito 3356.

Aparte de estos sarcófagos de plomo tenemos que referirnos a otros materiales que van a ir completando el catálogo perteneciente a este momento paleocristiano que se da en Itálica.

De la importancia que tuvo el cristianismo en Itálica se desprende la función que cumplieron algunos de estos materiales. Algunas tumbas aparecen selladas con mosaicos y pinturas a los que su atribuido carácter cristiano le confieren una función sacra. La aparición de estas tumbas con mosaicos que contienen una alegoría cristiana hablan seguramente de la mentalidad y de las nuevas ideas religiosas que estaban asentándose 
en el Imperio. La descripción de estos mosaicos y pinturas nos va a dar una idea de esta mentalidad religiosa imperante, seguramente, desde los siglos anteriores, aunque los testimonios arqueológicos no puedan constatarse hasta por lo menos el siglo IV d.C.

El mosaico de Antonia Vetia representa a la difunta de tres cuartos de perfil sentada en un taburete con almohadón rojo, teniendo entre sus manos un pájaro. La figura a la que le falta la cabeza está entre dos árboles o espigas. A la derecha del taburete encuadrada por una línea, está el epígrafe en tesselas azul cobalto, bastantes de cuales faltan. La mitad inferior del mosaico en decoración dispuesta en sentido contrario a la de la mitad superior, representa u caballo sobre línea y un pájaro picoteando una flor, llenando el campo de flores y tallos. Todo dentro de una orla de mosaico gris.

Existen otros mosaicos con esta misma decoración, a la que hay que añadirle distintos animales como los peces, palomas. Este mosaico perteneció a la tumba de María Severa, la cual tenía también una pintura en la que vuelve a repetirse los mismos motivos decorativos.

Las dos inscripciones que aparecen carecen en su fórmula funeraria del D. M. S. que caracterizaba las inscripciones funerarias de los paganos y que aparecen en Itálica hasta el siglo III d.C.

Todos estos materiales arqueológicos encuadrados dentro de una misma cronología del siglo IV d.C, constatan que es este siglo el que se empiezan a plasmar la mentalidad cristiana que imperante desde algunos siglos antes, no es reflejada quizás por la realidad socio- política del Imperio.

\section{CONCLUSIONES}

Es evidente que parte de los materiales aquí presentados, son comunes a otros muchos que han aparecido en ciudades romanas de gran parte de Imperio Romano.

Citar los materiales arqueológicos es importante ya que podemos rastrear sus orígenes y conocer cual ha sido su evolución a través de los primeros siglos de implantación del cristianismo.

Los sarcófagos de plomo encontrados en Itálica son parecidos a otros muchos hallados en otras ciudades del occidente romano. Baste con poner dos ejemplos cercanos a Itálica, uno es la ciudad romana de Arva, cuyos sarcófagos aparecen citados por J. Bonsor en un contexto funerario y con una tipología de tumbas igual a la de Itálica (Bonsor 1923: 195).

En Itálica tenemos la suerte de conocer el contexto arqueológico en que aparecen. La tipología de estructuras funerarias asociadas a estos sarcófagos en la necrópolis es muy homogénea, se trata de cuatro muros de ladrillos, normalmente enlucidos en su interior y cuya cubierta está compuesta por varias losas de ladrillos. Esta homogeneidad en las estructuras funerarias hablan de cronología igualitaria para la mayoría de ellas centrada en los siglos III y IV d.C.

Los motivos más repetidos en los sarcófagos de Itálica son vegetales como tallos serpenteantes alternando con hojas (a veces con tallos de los que parten ramos de cinco vástagos en los espacios inferiores), discos, lazos, y geométricos. También es posible la combinación de ambos.

Muchos de estos motivos se repiten en sarcófagos de otros lugares del Imperio, así lo demuestra el conjunto de sarcófagos de plomo del Museo Nacional del Líbano (Chéhab 1935: 51). Los motivos decorativos vegetales y geométricos son muy parecidos, aunque estos sarcófagos del Líbano tienen representaciones antropomorfas que aún no han aparecido en Itálica.

Si se producen diferencias en las zonas en las que se decora el sarcófago. Los encontrados hasta el momento en Itálica solo van decorados en la tapa y en el reborde de la misma y estos hallados en la parte oriental de imperio se suelen decorar además de la tapa, los frontales de los mismos. 
A pesar de estas coincidencias, no es factible pensar en una importación de estos sarcófagos desde la zona oriental del Imperio, máxime cuando la Península Ibérica contaba con minas de plomo. Por tanto, creemos que estos sarcófagos proceden de talleres locales, aunque esta similitud de modelos, parece deberse a unas modas de las que también escribe M. Chéhab (Chéhab 1935: 66).

Estas mismas tumbas que contenían los sarcófagos de plomo, fueron testigos de los otros vestigios cristianos de esta necrópolis de Itálica.

La transcripción de la monografía de Fernández López que hemos realizado en parte de este artículo, nos revela la existencia de varias losas de barro con símbolos eminentemente cristianos comoel alfa, la omega o el chrismón. Estos símbolos adoptados por el cristianismo se reflejan en las estructuras funerarias como elementos identificadores de una religión que cada vez se iba manifestándose abiertamente entre la sociedad romana, y la prueba de ello es la plasmación de la creencias del difunto que manifestaba en su lecho de muerte.

Otros ejemplos de esto que hablamos son las pinturas y los mosaicos funerarios hallados en Itálica. La idea de cubrir una tumba con un mosaico en el que se representa la difunta sentada y rodeada de una simbología eminentemente cristiana, vuelve a hacer referencia a esta manifestación pública de su religión.

Los símbolos reflejados en estos mosaicos y pinturas son recreados con gran asiduidad y pueden observarse también en laudas sepulcrales como la de Balería en Mallorca.

La presencia de pájaros como las palomas, de flores, etc.., se repiten en varios de estos mosaicos y pinturas. La interpretación de estos materiales arqueológicos proceden de la propia consideración cristiana de los mismos, así y por poner un solo ejemplo, tenemos la clara interpretación de la paloma, símbolo eminentemente cristiano que representa al Espíritu Santo.

Más difícil es hacerse una idea de los dos estructuras encontradas por Fernández López en el transcurso de estos trabajos.

La primera que hemos descrito y que su excavador la describe como una basílica cristiana primitiva, respondería posiblemente y aunque no tenemos ni un simple plano, a una de estas basílicas. El ábside, la nave alargada y dividida en tres, etc.. pueden dar pie a pensar, en que fuera una basílica paleocristiana. En la Península Ibérica conocemos basílicas con una planta parecida a la que nos describe Fernández López, pero debido a la escasa información que poseemos, nada podemos asegurar.

Otra interpretación nos la proporciona A. García y Bellido ya que apunta que podría tratarse de una: "cripta mithraica, pues testimonios de este culto se han hallado en Itálica" (García y Bellido 1960: 123)

La siguiente estructura a la que nos referimos, es la que Fernández López denomina como una "cruz griega de hermosísima proporciones". Tenemos un pequeño dibujo que aparece en su monografía en el que se observa una estructura en forma de $T$ a la que parece que se le añade una especie de pilares estriados a cada uno de los lados y que García y Bellido define como "una mensa para banquete funerarios, frecuente tanto entre paganos como entre cristianos primitivos" (García y Bellido 1960: 128). 
UN ASPECTO DEL CRISTIANISMO EN ITÁLICA Y SU PLASMACIÓN EN EL REGISTRO FUNERARIO...

\section{BIBLIOGRAFÍA}

ABAD CASAL, L. (1979): Pinturas romanas de Sevilla. Sevilla.

ALONSO SÁNCHEZ, M.A. (1978): "Orígenes del cristianismo hispano", Boletín de la Asociación Española de Arqueología 10: 41-45.

ARCE, J. (1982): El último siglo de la España romana: 284-409. Madrid.

ARCHER MILTON, H. La Itálica. (inédita).

CABALLOS RUFINO, A. (1994): Itálica y los italicenses. Sevilla.

CANTO Y DE GREGORIO, A.M. (1982): "Excavaciones en el "Pradillo" (Itálica, 1974): Un barrio tardío", Excavaciones Arqueológicas en España 121: 225-242. (1985): Epigrafía romana de Itálica. Tesis doctoral. Inédita.

CHEHAB, M. (1935): "Sarcophages en plomb du Musée National Libanais", Syria 16: 51 - 72.

COCHET, A. (1978): "Les sarcofages de plomb du Musée de Rouen. Comparaison avec d'autres sarcophages du Sud-Est de la France", Actes du Colloque International d'archéologie: 217-233.

COLLANTES DE TERÁN, F. Manuscritos depositados en el Departamento de Prehistoria y Arqueología de la Universidad de Sevilla. (inéditos).

CORZO SÁNCHEZ, R.(1994): El teatro. Granada.

DEL AMO, M.D. (1979): Estudio crítico de la necrópolis paleocristiana de Tarragona. Tarragona.

DELA BARRERA ANTÓN, J.L.(1995): "Un conjunto de enterramientos paleocristianos en la necrópolis de Santa Eulalia (Mérida), Revista de Estudios Extremeños 51:

DELOS RÍOS, R.A.(1911): "Itálica, el misterio de su destrucción y su ruina", La España Moderna: 92-111. DÍAZ Y DÍAZ, M. (1967): En torno a los orígenes del cristianismo hispano, en las raíces de España. Madrid. FERNÁNDEZ LÓPEZ, M. (1904): Excavaciones en Itálica, 1903. Sevilla.

GARCÍA IGLESIAS, L. (1974): “Aspectos económicos sociales de la Mérida visigótica”, Revista de Estudios Extremeños XXX: 321-362.

GARCÍA MAZAS, J.(1962): El poeta y la escultora. Madrid.

GARCÍA Y BELLIDO, A. (1960): Colonia Aelia Augusta. Madrid.

GONZÁLEZ FERNÁNDEZ, J.(1991): Corpus de inscripciones latinas de Andalucía. Vol. II Sevilla. Tomo II. La Vega (Itálica). Sevilla.

ÍNIGUEZ HERRERO, J.A. (1977): Síntesis de arqueología cristiana. Ávila.

MATEOS CRUZ, P. (1999): La basílica de Santa Eulalia de Mérida. Madrid.

MOMIGLIANO, A. (1989): El conflicto entre el paganismo y el cristianismo en el siglo IV. Madrid.

PARIS, P.; BONSOR, J.; LAUMONIER, A.; LAUMONIER, R. y DE MERGELINA, C. (1923): Fouilles de Belo, (Bolonia, provence de Cadix), (1917-1921). Vol. II: La nécropole. Burdeos.

PELLICER CATALÁN, M. (1999): "Panorama de la arqueología en Itálica", Boletín de la Real Academia Santa Isabel de Hungría: 145-165.

SAINZ DE ARIZMENDI, C. (1907): "Los restos romanos de Itálica", Revista de Archivos, Bibliotecas y Museos 10: 88-93.

ZEVALLOS, F.(1886): La Itálica. Sevilla. 